Detection of cobalamin deficiency using the urinary methylmalonic acid test by gas chromatography mass spectrometry

In their recent paper Chanarin et al ${ }^{1}$ state that urinary methylmalonic acid (MMA) concentrations are not an early sign for the detection of cobalamin ( $\mathrm{Cbl}$ ) deficiency. They base their opinion on a study that used gas chromatography as a means to quantify urinary MMA. Methodology using gas chromatography only lacks the specificity and sensitivity to accurately differentiate slightly increased concentrations of urinary MMA from normal amounts of urinary MMA.

Measurement of urinary MMA by gas chromatography mass spectrometry (GC/ MS) is a highly sensitive and specific test for detecting $\mathrm{Cbl}$ deficiency. ${ }^{2-5}$ Norman et al ${ }^{2}$ identified 54 consecutive inpatients with $\mathrm{Cbl}$ deficiency using the urinary MMA assay by GC/MS and $20 \%$ had a normal hematocrit at diagnosis. In a prospective clinical evaluation of the urinary MMA test by GC/MS Matcher et $\mathrm{ll}^{3}$ studied inpatients with obvious $\mathrm{Cbl}$ deficiency and $\mathrm{Cbl}$ deficient patients. They determined the assay to have a sensitivity of $100 \%$ and a specificity of $99 \%$. Specker et $a l^{4}$ used the urinary MMA assay by GC/MS to detect $\mathrm{Cbl}$ deficiency in a non-anaemic strict vegetarian population. More recently, the high sensitivity of the assay was demonstrated by identifying $\mathrm{Cbl}$ deficient non-anaemic persons over the age of 65 of whom $40 \%$ had serum Cbl concentrations in the normal range. ${ }^{5}$

False negative results have not been reported for the urinary MMA assay by GC/MS. ${ }^{2-5}$ It should be noted, however, that a "gold standard" test for Cbl deficiency does not exist because neither the Schilling test nor the serum total $\mathrm{Cbl}$ assay is a functional test. The serum MMA assay lacks specificity because the test can give falsely high values in patients with renal insufficiency or intravascular volume depletion. The urinary MMA test by GC/MS is normalised to urinary creatinine, and falsely high urinary MMA concentrations have not been reported in patients with renal insufficiency. ${ }^{5}$

Thus the urinary MMA test by GC/MS detects early $\mathrm{Cbl}$ deficiency, can routinely identify non-anaemic $\mathrm{Cbl}$ deficiency and is perhaps the "gold standard" for identifying true functional $\mathrm{Cbl}$ tissue deficiency.

ERIC J NORMAN Monarch Foundation 400 Oak Street Cincinnati,
Ohio 45219

1 Chanarin I, Deacon R, Lumb M, Perry J. Cobalamin and folate: Recent developments. f Clin Pathol 1992;45:277-83.

2 Norman EJ. Gas chromatography mass spectrometry screening of urinary methylmalonic acid: early detection of vitamin $B_{12}$ (cobalamin) deficiency to prevent permanent neurologic disability. GC/MS News 1984;12 $120-9$.

3 Matchar DB, Feussner JR, Millington DS, Wilkinson RH Jr, Watson DJ, Gale D. Isotope-dilution assay for urinary methylmalonic acid in the diagnosis of vitamin $B$ malonic acid in the diagnosis of vitamin $B_{12}$ Ann Int Med 1987;106:707-10.

4 Specker BL, Miller D, Norman EJ, Greene H, Hayes KC. Increased urinary methylmalonic acid excretion in breast fed infants of vegetarian mothers and an identification of an acceptable dietary source of vitamin $\mathrm{B}_{12}$. Am f Clin Nutr 1988;47:89-92.

5 Norman EJ, Morrison JA. Screening elderly populations for cobalamin (vitamin $\mathbf{B}_{12}$ ) deficiency using the urinary methylmalonic acid assay by gas chromatography mass spectrom-
etry. Am $\mathcal{F}$ Med.

\section{Acanthamoeba keratitis}

The case report on Acanthamoeba keratitis and subsequent response ${ }^{2}$ require elaboration.

Acanthamoeba is a ubiquitous free-living protozoan which occurs in a wide range of environmental niches including domestic tap water. Inhalation of the organism or its penetration into open wounds can lead to development of granulomatous amoebic encephalitis, a chronic central nervous system infection with a prolonged clinical course which in some circumstances may prove fatal. ${ }^{3}$ Acanthamoeba has been cultured from the nasopharynx of normal, healthy subjects and there are a significant number of people with antibody against the organism.

Acanthamoeba keratitis was first recorded in 1974. A large number of cases have been reported subsequently, perhaps as a consequence of increased recognition of the condition. As was highlighted previously, however, awareness of the role of these amoebae in clinical diagnosis and practice is limited. Earlier reports suggested an association between keratitis and trauma with a foreign body contaminated with Acanthamoeba. Currently, most presentations are from contact lens wearers, increasingly with so-called "disposable" contact lenses, where these have been immersed in inappropriate disinfecting systems. ${ }^{4}$ For example, commercially available chlorine systems will fail to kill Acanthamoeba cysts ${ }^{5}$ if the latter are present in the reusable contact lens storage case. ${ }^{6}$ The condition is more frequently detected in young immunocompetent persons who wear contact lenses for cosmetic purposes, and who have poor compliance with contact lens disinfection regimens. In one study, about $7 \%$ of contact lens cases contained viable cysts of Acanthamoeba. ${ }^{7}$ The incidence of Acanthamoeba keratitis in contact lens wearers in the USA is of the order of 1:250 000

Recognition of early ocular disease in contact lens wearers due to Acanthamoeba is all important. It initially presents as a punctate or dendriform epitheliopathy and may proceed to stromal invasion. Acanthamoeba keratitis is therefore most often misdiagnosed initially as herpes simplex keratitis and treated as such with antiviral agents and possibly corticosteroids. If such treatment fails the next diagnosis is often of fungal infection. Definitive diagnosis of Acanthamoeba keratitis from superficial corneal scrapings may prove inconclusive, because the organism can be present deeper within the stroma. In such circumstances corneal biopsy extending deeper into the stromal abscess is required; excised tissue should then be subjected to light and transmission electron microscope examination and cultured for the presence of viable amoebae.

For routine culture, a non-nutrient agar $(1 \cdot 5 \%)$, prepared at least 24 hours in advance, is seeded with heat-killed Escherichia coli or Klebsiella aeruginosa. Corneal scraping or tissue is gently spread across the central area of two separate plates, one to be incubated at $25^{\circ} \mathrm{C}$ and the other at $33^{\circ} \mathrm{C}$. If the specimen is to be forwarded to a reference laboratory, it should be placed in sterile isotonic saline and kept at room temperature before despatch. Often clinical specimens which contain Acanthamoeba, and amoebae which have been subjected to topical chemotherapy or corticosteroids, require supplements to promote growth and development of the amoebae in culture. If necessary, various biochemical or molecular biological methods can be used to provide unequivocal speciation and strain identification of the pathogenic Acanthamoeba.

Medical treatment with combined topical treatment comprising propamidine isethionate plus neomycin at an early stage can be successful. ${ }^{9}$ If unrecognised, the infection progresses to a ring abscess when medical treatment is often unsuccessful and a corneal graft, including on occasion, a second graft, is required. Anti-acanthamoebic drugs at this stage may result in emergence of temperature sensitive and drug resistant strains of the organism. ${ }^{10}$ Sensitivity testing of cultured clinical isolates must therefore be performed.

J HAY

Acanthamoeba Research Laboratory, Glasgow Royal Infirmary, Wolfson Centre, Level 531 Taylor Street, Glasgow G4 ONA CM KIRKNESS

Tennent Institute of Ophthalmology, Western Infirmary, Glasgow G11 6WT

1 Anderson D, Soo SS, Towler H. Acanthamoeba keratitis: experience in a non-specialist laboratory. F Clin Pathol 1991;44:699.

2 Casemore DP, Warhurst DC. Acanthamoeba keratitis. $\mathcal{F}$ Clin Pathol 1992;45:367.

3 Martinez AJ. Free-living amebas: Natural history, prevention, diagnosis, pathology, and treatment of disease. Boca Raton, Florida: CRC Press, Inc, 1985.

4 Seal DV, Hay J. Contact lens disinfection and Acanthamoeba: problems and practicalities. Pharmacol f 1992;248:717-9.

5 Seal DV, Hay J, Devonshire P, Kirkness CM. Acanthamoeba and contact lens disinfection: should chlorine be discontinued? $\mathrm{Br} f$ Ophthalmol (in press).

6 Seal DV, Stapleton F, Dart J. Possible environmental sources of Acanthamoeba spp in contact lens wearers. Br $\mathcal{F}$ Ophthalmol 1992;76: 424-7.

7 Larkin DFP, Kilvington S, Easty DL. Contamination of contact lens storage cases by Acanthamoeba and bacteria. $\mathrm{Br} \quad \mathcal{F}$ Ophthalmol 1990;74:133-5.

8 Stehr-Green JK, Bailey TM, Visvesvara GS. The epidemiology of Acanthamoeba keratitis in the United States. Am $\mathcal{F}$ Ophthalmol 1989; 107:331-6.

9 Wright P, Warhurst D, Jones BJ. Acanthamoeba keratitis successfully treated medical moeba keratitis successfully treated

10 Ficker L, Seal D, Warhurst D, Wright P. Acanthamoeba keratitis-resistance to medical therapy. Eye 1990;4:835-8

\section{Factors affecting the maintenance dose} of warfarin

James et $a l^{1}$ have confirmed the observations of others that elderly patients require less warfarin than younger patients to achieve the same intensity of anticoagulation..$^{2-4}$ They suggest that the age dependency of dose should perhaps be taken into account in judging initial dose. We have already studied this question ${ }^{4}$ and have demonstrated that if a flexible induction dose regimen such as that of Fennerty $e t a{ }^{\bar{T}}$ is used elderly patients can safely start on the same initial dose as other patients. Should a fixed dosage schedule be used this might not necessarily be so. University of London,
St Mary's Hospital Medical School, Department of Haematology, Norfolk Place,
Paddington, London W2 IPG 